\title{
Correction to: The difference in sleep, sedentary behaviour, and physical activity between older adults with 'healthy' and 'unhealthy' cardiometabolic profiles: a cross-sectional compositional data analysis approach
}

Declan John Ryan ${ }^{1,2^{*}}$, Jorgen Antonin Wullems ${ }^{1,3}$, Georgina Kate Stebbings ${ }^{1}$, Christopher lan Morse ${ }^{1}$, Claire Elizabeth Stewart ${ }^{4}$ and Gladys Leopoldine Onambele-Pearson ${ }^{1}$

\section{Correction to: European Review of Aging and Physical Activity (2019) 16:25}

https://doi.org/10.1186/s11556-019-0231-4

Following publication of the original article [1], the authors reported an error on the content of Availability of data and materials section in their paper. It should be corrected from:

"Upon acceptance of this manuscript, datasets generated and/or analysed during the current study will be available from the Manchester Metropolitan University Repository. Confirmation of web link will be provided at manuscript acceptance."

to

"Data associated with this publication can be accessed via the Manchester Metropolitan University repository using the following link: https://url defense.proofpoint.com/v2/url?u=http-3A_e-2 Dspace.mmu.ac.uk 624523\&\&d=DwIGaQ\&c=vh6 FgFnduejNhPPD0fl_yRaSfZy8CWbWnIf4XJhSqx
8\&r=J-U_lVgGXMYKEbxyTbwI9N9azQNeNZu2 KgOlMMyTps4\&m=wPuRk8o0Ra0spVIXwSLiGSX6j3Pd0Hx0zZgX-lhWZU\&s=7ZxsFuAjm7ONZ GaY430ueWMctP_uWnug1fruBni719I\&e="

Author details

1Department of Exercise and Sport Science, Musculoskeletal Sciences and Sport Medicine (MSSM) Research Centre, Manchester Metropolitan University, Manchester M15 6BH, UK. ${ }^{2}$ Science, University of Northampton, Northampton, Northamptonshire NN1 5PH, UK. ${ }^{3}$ Department of Rehabilitation Sciences, Musculoskeletal Rehabilitation Research Group, KU Leuven, 3000 Leuven, Flanders, Belgium. ${ }^{4}$ Research Institute for Sport and Exercise Sciences, Liverpool John Moores University, Liverpool, Merseyside L3 3AF, UK.

Published online: 30 January 2020

Reference

1. Ryan, et al. The difference in sleep, sedentary behaviour, and physical activity between older adults with 'healthy' and 'unhealthy' cardiometabolic profiles: a cross-sectional compositional data analysis approach. Eur Rev Aging Phys Act. 2019;16:25 https://doi.org/10.1186/s11556-019-0231-4.

The original article can be found online at https://doi.org/10.1186/s11556019-0231-4

* Correspondence: Declan.ryan@northampton.ac.uk

${ }^{1}$ Department of Exercise and Sport Science, Musculoskeletal Sciences and Sport Medicine (MSSM) Research Centre, Manchester Metropolitan University, Manchester M15 6BH, UK

${ }^{2}$ Science, University of Northampton, Northampton, Northamptonshire NN1 $5 \mathrm{PH}, \mathrm{UK}$

Full list of author information is available at the end of the article

(c) The Author(s). 2020 Open Access This article is distributed under the terms of the Creative Commons Attribution 4.0 International License (http://creativecommons.org/licenses/by/4.0/), which permits unrestricted use, distribution, and reproduction in any medium, provided you give appropriate credit to the original author(s) and the source, provide a link to the Creative Commons license, and indicate if changes were made. The Creative Commons Public Domain Dedication waiver (http://creativecommons.org/publicdomain/zero/1.0/) applies to the data made available in this article, unless otherwise stated. 